\title{
Can consumption of raw vegetables decrease the count of sister chromatid exchange? Results from a cross-sectional study in Krakow, Poland
}

\author{
Aleksander Galas • Antonina Cebulska-Wasilewska
}

Received: 4 September 2013/Accepted: 1 April 2014/Published online: 17 April 2014

(C) The Author(s) 2014. This article is published with open access at Springerlink.com

\begin{abstract}
Background Sister chromatid exchange (SCE) is a widely used sensitive cytogenetic biomarker of exposure to genotoxic and cancerogenic agents. Results of human monitoring studies and cytogenetic damage have revealed that biological effects of genotoxic exposures are influenced by confounding factors related to life-style. Vegetable and fruit consumption may play a role, but available results are not consistent. The purpose of the study was to investigate the effect of consumption of raw and cooked vegetables and fruits on SCE frequency.

Methods A total of 62 participants included colorectal cancer (CRC) patients, hospital-based controls and healthy laboratory workers. SCE frequency was assessed in blood lymphocytes. Frequency of vegetable and fruit consumption was gathered by structured semi-quantitative food frequency questionnaire.

Results SCE frequency was lowest among hospital-based controls $(4.4 \pm 1.1)$, a bit higher in CRC patients $(4.5 \pm 1.0)$ and highest among laboratory workers $(7.4 \pm 1.2) \quad(p<0.05)$. Multivariable linear regression showed a significant inverse effect $(b=-0.20)$ of raw vegetable consumption, but not so for intake of cooked vegetables and fruits.

Conclusions The results of the study have shown the beneficial effect of consumption of raw vegetables on
\end{abstract}

\section{A. Galas $(\bowtie)$}

Department of Epidemiology, Chair of Epidemiology and Preventive Medicine, Jagiellonian University Medical College, 7 Kopernika St, Kraków, Poland

e-mail: mygalas@cyf-kr.edu.pl; aleksander.galas@uj.edu.pl

\section{A. Cebulska-Wasilewska}

Department of Radiation and Environmental Biology, Institute of Nuclear Physics, Polish Academy of Sciences,

152 Radzikowskiego St, Kraków, Poland disrupted replication of DNA measured by SCE frequency, implying protection against genotoxic agents. Further effort is required to verify the role of cooked vegetables and fruits.

Keywords Biomarker - Sister chromatid exchange · Colorectal cancer - Controls - Raw and cooked vegetables . Fruits

\section{Background}

There is a general consensus that cancers develop as a consequence of an accumulation of DNA damage and a subsequent change in function of oncogenes and tumor suppressor genes. The DNA damage depends on type, concentration, and duration of exposure to carcinogens, and on effectiveness of cellular defense (e.g., antioxidants) as well as metabolic detoxification and repair mechanisms [1]. After exposure to genotoxic agents, DNA may present sister chromatid exchange (SCE).

SCE is a process whereby, during DNA replication, two sister chromatids break and rejoin with one another, physically exchanging regions of the parental strands in the duplicated chromosomes. This process is considered to be conservative and error-free, since no information is generally altered during reciprocal interchange by homologous recombination.

SCE is assessed and scored after the second S phase in the presence of the thymidine analog 5-bromodeoxyuridine (BrdU) [2]. The SCE assay is one of various methods in genetic toxicology and human population cytogenetic monitoring, being an indicator of disrupted replication or wrong chromatid segregation, and is frequently used as a sensitive cytogenetic biomarker of exposure to chemical 
genotoxic agents [3]. It is also considered as a sensitive measure of individual susceptibility to the effects of mutagens and also has been suggested as a possible indicator of an increased cancer risk [4].

SCEs appear as the consequence of so-called susceptibility, which is the effect of both the effectiveness of DNA repair mechanisms and the genotoxic effect of mutagens. The most common mechanism of genotoxicity is the generation of free radicals. Reactive oxygen species (ROS) may lead to formation of hydroxyl radicals, which, being highly destructive, result in direct damage to the DNA [5] in the form of strand breaks (single or double), oxidized purines and/or pyrimidines, as well as alkali labile sites [6], and these oxidative modifications have been observed in several conditions including cancer, cardiovascular disease and other age-related changes [7]. Several mechanisms have evolved that protect against effects of ROS. These include (1) enzymatic and non-enzymatic mechanisms that prevent formation of radicals, (2) pathways responsible for removal of radicals before damage occurs and (3) elimination of consequences of oxidative damage by either repair or elimination of damaged molecules, which all together prevent mutations [8].

It has been demonstrated that diet, especially plant components, has antioxidant properties. Diet rich in antioxidant nutrients may reduce the risk of several cancers [9]. However, in spite of extensive investigation of an effect of diet, especially of vegetables and fruits in the development of cancer, they are currently considered only as possibly or probably preventive [9]. Results are somewhat inconsistent, as a consequence of different study designs used and different end points considered [9-18]. Overall, a majority of case-control, some cohort and only a few intervention studies have supported a positive effect [9]. Reports from basic experimental research investigating the protective effect of dietary components on the DNA are also heterogeneous. There are studies showing beneficial effect of extracts from broccoli [10], dietary polyphenols [11] and a variety of dietary micronutrients [12]. Contrarily, there are also recent investigations showing no effect of consumption of vegetables and plant oil [13], brassica vegetables [14], vitamin C [15] and some other dietary components [16-18].

Nevertheless, fruits and vegetables are dietary components rich in vitamins and phytochemicals. Both are potentially protective and have shown effects by inhibition of DNA damage, cellular injury and degeneration [19, 20]. All in all, if fruits and vegetables are protective against DNA damage, this should be observed in vivo among different groups of individuals as a dose-dependent relationship between level of consumption and frequency of DNA damage or of endpoints related to DNA damage, such as SCEs.

\section{Purpose}

The purpose of the study was to assess the association between consumption of vegetables and fruits and the frequency of SCEs across individuals diagnosed with colorectal cancer and cancer-free controls.

\section{Materials and methods}

The cross-sectional investigation was carried out in 2011-2013 as a part of a larger case-control study. The design of the study has been described elsewhere [21, 22]. In brief, participants were individuals diagnosed with colorectal cancer $(n=22)$, some other acute chronic conditions $(n=16)$ and healthy laboratory workers $(n=24)$. Cases were patients newly diagnosed with sporadic (only) histologically confirmed adenocarcinomas of colorectal cancer treated at the I Chair of General Surgery and Department of Gastroenterological Surgery, Jagiellonian University Medical College, Krakow, Poland. In the second group, there were patients admitted to the University Hospital, Krakow, Poland, due to other cancer-unrelated conditions, and in the third-laboratory workers. After written consent had been obtained, participants were asked about basic characteristics and dietary habits including their average consumption of raw and cooked vegetables and fruits.

\section{Dietary questionnaire}

Dietary habits were assessed by a semi-quantitative food frequency questionnaire (SFFQ) which had been developed in cooperation with the German Cancer Research Centre in Potsdam, where an introductory part of the European Prospective Investigation into Cancer and Nutrition (EPICPotsdam) project had been performed. In total, 148-dietary items were included in questions about consumption of cereals, dairy products, bread, type and cuts of meat and fish, fresh fruits (summer/winter time), salads and fresh and cooked vegetables, rice or pasta, soups, sweets, baked goods, drinks and others. For each food or beverage item, a commonly consumed portion size was specified by standardized photographs. Next, respondents were asked to provide information about frequency of consumption. For the research, information about usual (habitual) consumption over the period of 1 year by calendar seasons was gathered by trained interviewers. Patient cases were asked about their dietary patterns prior to the onset of gastrointestinal symptoms (if present) or prior to the beginning of the diagnosis process. The validity and reproducibility of the questionnaire was assessed and published [23]. Questions aimed to assess habitual consumption of vegetables 
and fruits have been provided in the "Appendix". In the analysis, an average number of servings were analyzed. The size of a serving was standardized to the value of $80 \mathrm{~g}$ of eatable parts of fruits or vegetables.

For the subgroup of 62 individuals, blood samples were taken for an analysis of SCEs.

The study was conducted in accordance with the ethical principles of the Declaration of Helsinki and was approved by the Bioethical Committee of Jagiellonian University (number KBET/115/B/2011).

\section{Sister chromatid exchange assay}

Blood samples were taken from all enrolled individuals and quickly transported to the laboratory unit. Lymphocytes were separated within an hour and cultured. All samples were incubated at $37{ }^{\circ} \mathrm{C}$ in RPMI 1640 medium with $20 \%$ fetal calf serum, antibiotics and $0.075 \mathrm{mM}$ BrdU. Then, lymphocytes were stimulated by phytohaemagglutinin (PHA) and cultured for $72 \mathrm{~h}$. Two hours before the end of culturing, $0.1 \mu \mathrm{l} / \mathrm{ml}$ of colcemid solution (to stop dividing cells in metaphase) was added. Next cells were prepared following the standard procedure [24]. Slides were coded blindly. Finally, 50 well-spread second metaphases were analyzed for every participant.

Proliferation rate index was assessed from a distribution of cells scored in the first $\left(M_{1}\right)$, second $\left(M_{2}\right)$ and third $\left(M_{3}\right)$ division according to the following standard formula: $\mathrm{PRI}=\left(M_{1}+2 \times M_{2}+3 \times M_{3}\right) /\left(M_{1}+M_{2}+M_{3}\right) . \quad$ In order to determine PRI, a minimum of 100 consecutive metaphase cells per patient were evaluated. The number of cell cycles performed by each cell was determined, considering that when cells completed only one cell cycle $\left(M_{1}\right)$ both chromatids are labeled and all the chromosomes are uniformly strained. After second division $\left(M_{2}\right)$, DNA of one chromatid is labeled in every chromosome, showing a characteristic sister chromatid differentiation pattern. After three cell cycles $\left(M_{3}\right)$, approximately half of the chromosomes in a cell possess harlequin staining.

\section{Statistical analysis}

Basic characteristics were presented as means and standard deviations, medians and interquartile ranges. Differences were tested by one-way ANOVA (analysis of variance) for normally distributed and by Kruskal-Wallis test for skewed variables. Categorized variables were tested by the chisquare test, or in a case of expected values of $<5$, by the Fisher's exact test. For the comparison of SCEs across groups of vegetable and fruit consumption, the groups have been created by median-equal cutoffs. The fit to the normal distribution has been tested by the Shapiro-Wilk test, and, as the distributions fitted the normal distribution, the $t$ test has been used. Linear regression was used to test the effect of consumption of vegetables and fruits on the SCE count. There were three main linear models investigated. First, a simple univariable model used to test the general pattern between dependent (SCE) and independent (vegetables or fruits) variables. Next, age and sex were used as covariates to verify the presence of relationship considering these two personal characteristic as main confounding variables; and finally, in the third model, we additionally used the diagnosis of colorectal cancer to account for cancer/non-cancer genetic susceptibility and vitamin supplementation (yes/ no) as the SCE frequency might depend also on the antioxidative effect of some vitamins. Finally, all relevant variables were put together in one model. All analyses were performed using the statistical software package Stata/IC 11.2 for Windows, Stata Corp LP. A $p$ value below 0.05 was considered statistically significant.

\section{Results}

In total, 62 individuals were recruited and investigated in the study. There were three groups of individuals: 22 colorectal cancer patients, and in total 40 controls, including 16 hospital patients admitted due to acute conditions and 24 apparently healthy laboratory workers. The first two groups were part of a larger case-control study $[21,22]$ for which a subsample was randomly chosen for the SCE evaluation. Subsequently, a group of controls were enlarged by available blood samples of healthy laboratory staff.

Basic characteristics of the study participants are presented in Table 1 . Groups varied significantly according to age (laboratory workers were younger), consumption of raw vegetables (highest amount among hospital-based controls, lowest in laboratory staff), vitamin supplementation (highest among laboratory staff, lowest among hospital controls).

Considering the average SCE frequency per cell, the highest was observed among laboratory workers (7.4 \pm 1.2$)$, next among CRC patients $(4.5 \pm 1.0)$ and the lowest in hospital-based controls $(4.4 \pm 1.1)$. Differences between laboratory workers and the two remaining groups were statistically significant. Otherwise, proliferation rate index (PRI) was significantly lowest in the group of laboratory staff $(2.0 \pm 0.4)$ as compared to that in the two other groups, and highest among CRC patients $(2.4 \pm 0.4)$ (Table 1).

As the main purpose of the investigation was to assess the role of vegetables and fruits, a linear regression model was use to assess the association between the aforementioned dietary components and SCE frequency. Vegetables were investigated as raw and cooked separately, and it was 
Table 1 Basic characteristics of study participants

$C R C$ colorectal cancer, $H B C$ hospital-based controls, $L S$ laboratory staff, SCE sister chromatid exchange, $P R I$ proliferation rate index, $d f$ degrees of freedom, Chi chi-square test, $K W$ Kruskal-Wallis test, $A$ one-way anova, $F$ Fisher's exact test

* One-way ANOVA, CRC versus LS $p=0.064$; HBC versus LS $p=0.052$

** One-way ANOVA, CRC versus LS $p<0.001 ; \mathrm{HBC}$ versus LS $p<0.001$

*** One-way ANOVA, CRC versus LS $p=0.002$; HBC versus LS $p=0.026$

\begin{tabular}{|c|c|c|c|c|}
\hline & $\begin{array}{l}\text { CRC patients } \\
(n=22)\end{array}$ & $\begin{array}{l}\text { Hospital-based } \\
\text { controls }(n=16)\end{array}$ & $\begin{array}{l}\text { Laboratory staff } \\
(n=24)\end{array}$ & $p$ \\
\hline \multicolumn{5}{|l|}{ Age } \\
\hline Mean (SD) & $57.9(10.1)$ & $58.8(12.6)$ & $39.8(12.7)$ & \multirow[t]{2}{*}{$p^{*}<0.001$} \\
\hline Median (Q1-Q3) & $60.0(49.0-66.0)$ & $63.5(52.5-67.5)$ & $34.5(28.0-52.5)$ & \\
\hline \multicolumn{5}{|l|}{$\operatorname{Sex}[n,(\%)]$} \\
\hline Males & $9(40.9 \%)$ & $8(50.0 \%)$ & $8(33.3 \%)$ & $d f=2$ \\
\hline Females & $13(59.1 \%)$ & $8(50.0 \%)$ & $16(66.7 \%)$ & $p^{\text {chi }}=0.573$ \\
\hline \multicolumn{5}{|c|}{ Raw vegetable consumption (servings/week) } \\
\hline Mean (SD) & $6.6(2.4)$ & $6.9(3.0)$ & $5.0(2.0)$ & \multirow[t]{2}{*}{$p^{*}=0.023$} \\
\hline Median (Q1-Q3) & $7.0(5.1-8.2)$ & $6.1(5.4-8.6)$ & $5.0(3.0-7.0)$ & \\
\hline \multicolumn{5}{|c|}{ Cooked vegetable consumption (servings/week) } \\
\hline Mean (SD) & $3.7(1.1)$ & $3.3(1.1)$ & $4.0(1.9)$ & \multirow[t]{2}{*}{$p^{\mathrm{KW}}=0.525$} \\
\hline Median (Q1-Q3) & $3.8(2.7-4.6)$ & $3.3(2.5-4.0)$ & $3.5(2.0-5.0)$ & \\
\hline \multicolumn{5}{|l|}{ Fruit consumption (servings/week) } \\
\hline Mean (SD) & $8.0(4.1)$ & $9.3(6.5)$ & $9.4(5.6)$ & \multirow[t]{2}{*}{$p^{\mathrm{A}}=0.629$} \\
\hline Median (Q1-Q3) & $8.3(4.5-9.9)$ & $7.6(5.5-11.9)$ & $7.5(5.0-15.0)$ & \\
\hline Vitamin supplementation $[n,(\%)]$ & $3(13.6 \%)$ & 0 & $10(41.7 \%)$ & $p^{\mathrm{F}}=0.004$ \\
\hline \multicolumn{5}{|l|}{ Smoker $[n,(\%)]$} \\
\hline No & $15(68.2 \%)$ & $10(62.5 \%)$ & $19(79.2 \%)$ & $d f=2$ \\
\hline Yes & $7(31.8 \%)$ & $6(37.5 \%)$ & $5(20.8 \%)$ & $p^{\mathrm{chi}}=0.491$ \\
\hline \multicolumn{5}{|l|}{ SCE } \\
\hline Mean (SD) & $4.45(0.99)$ & $4.40(1.11)$ & $7.39(1.23)$ & \multirow[t]{2}{*}{$p^{* *}<0.001$} \\
\hline Median (Q1-Q3) & $4.53(3.48-5.13)$ & $4.46(3.72-5.16)$ & $7.21(6.59-8.32)$ & \\
\hline PRI & $n=20$ & $n=10$ & $n=24$ & \\
\hline Mean (SD) & $2.38(0.42)$ & $2.36(0.31)$ & $1.95(0.40)$ & \multirow[t]{2}{*}{$p^{* * *}=0.001$} \\
\hline Median (Q1-Q3) & $2.52(1.99-2.67)$ & $2.46(2.29-2.54)$ & $2.00(1.62-2.25)$ & \\
\hline
\end{tabular}

Table 2 Relationship between vegetable and fruit consumption and SCE frequency

\begin{tabular}{lcllllllll}
\hline Consumption (servings/week) & $b^{1}$ & $p^{1}$ & $R_{\text {model 1 }}^{2}$ & $b^{2}$ & $p^{2}$ & $R_{\text {model 2 }}^{2}$ & $b^{3}$ & $p^{3}$ & $R_{\text {model 3 }}^{2}$ \\
\hline Raw vegetables & -0.21 & 0.019 & 0.09 & -0.22 & 0.003 & 0.45 & -0.14 & 0.025 & 0.60 \\
Cooked vegetables & 0.21 & 0.192 & 0.03 & 0.20 & 0.119 & 0.38 & 0.20 & 0.060 & 0.59 \\
Fruits & -0.003 & 0.941 & 0.000 & 0.001 & 0.976 & 0.36 & 0.01 & 0.694 & 0.56 \\
\hline
\end{tabular}

Linear regression for the whole sample of $n=62$

1-Univariable model: $b^{1}$-regression coefficient in univariable model, $p^{1}$ the $p$ value for the univariable model, $R_{\text {model } 1}^{2}$-the coefficient of determination of the univariable model

2-Multivariable linear regression, adjusted for age and sex: $b^{2}$-regression coefficient in the model, $p^{2}$ - the $p$ value for the model, $R_{\text {model } 2}^{2}$ the coefficient of determination of the model

3-Multivariable linear regression, adjusted for the covariates from the model 2 and vitamin supplementation, and the diagnosis of CRC: $b^{3}$ regression coefficient in the model, $p^{3}$-the $p$ value for the model, $R_{\operatorname{model} 3}^{2}$-the coefficient of determination of the model

observed that consumption of raw vegetables was associated with a significant decrease in SCE frequency in either univariable $(b=-0.21)$ or multivariable model $(b=$ $-0.14)$. Consumption of neither cooked vegetables nor fruits had a statistically significant effect on the SCE count (Table 2).

Additionally, the effect of raw vegetable consumption on the SCE frequency was also observed in the fully adjusted model, i.e., adjusted for cooked vegetables, fruits, vitamin supplementation, age, sex and a diagnosis of CRC; as a result, the observed regression coefficient was $b_{\mathrm{SCE}}=-0.17 \quad\left(p=0.009 ; R_{\text {model }}^{2}=\right.$ $\left.0.64 ; p_{\text {model }}<0.0001\right)$ and, when the PRI count was added $b_{\mathrm{SCE}}=-0.20\left(p=0.016 ; R_{\text {model }}^{2}=0.71\right.$; $\left.p_{\text {model }}<0.0001\right)$.

Finally, some comparisons across different levels of fruit and vegetable consumption (above and below median values) have been performed. These who consumed higher levels of raw vegetables presented lower levels of SCEs; however, differences were not statistically significant (Table 3). 
Table 3 SCE count across groups of consumption (the cutoffs between low and high are medians)

\begin{tabular}{|c|c|c|c|}
\hline & \multicolumn{3}{|c|}{ Level of raw vegetable consumption } \\
\hline & Low $<5.89$ servings/week & High $\geq 5.89$ servings/week & $p$ \\
\hline \multicolumn{4}{|c|}{ All groups together $(n=62)$} \\
\hline SCEs & $(n=31)$ & $(n=31)$ & \multirow{3}{*}{0.073} \\
\hline Mean (SD) & $5.91(1.77)$ & $5.23(1.84)$ & \\
\hline Median (Q1-Q3) & $5.46(4.28-7.45)$ & $5.00(3.50-6.60)$ & \\
\hline \multicolumn{4}{|l|}{ CRC patients $(n=22)$} \\
\hline SCEs & $(n=9)$ & $(n=13)$ & \multirow{3}{*}{0.348} \\
\hline Mean (SD) & $4.56(0.88)$ & $4.38(1.08)$ & \\
\hline Median (Q1-Q3) & $4.84(3.91-5.23)$ & $4.41(3.48-4.97)$ & \\
\hline \multicolumn{4}{|c|}{ Hospital-based controls $(n=16)$} \\
\hline SCEs & $(n=8)$ & $(n=8)$ & \multirow{3}{*}{0.252} \\
\hline Mean (SD) & $4.60(0.99)$ & $4.21(1.26)$ & \\
\hline Median (Q1-Q3) & $4.24(3.98-4.99)$ & $4.83(2.96-5.24)$ & \\
\hline \multicolumn{4}{|c|}{ Laboratory staff $(n=24)$} \\
\hline SCEs & $(n=14)$ & $(n=10)$ & \multirow{3}{*}{0.246} \\
\hline Mean (SD) & $7.53(1.01)$ & $7.18(1.51)$ & \\
\hline \multirow[t]{3}{*}{ Median (Q1-Q3) } & $7.51(6.67-8.15)$ & $6.79(5.97-8.89)$ & \\
\hline & \multicolumn{3}{|c|}{ Level of cooked vegetable consumption } \\
\hline & Low $<3.68$ servings/week & High $\geq 3.68$ servings/week & $p$ \\
\hline \multicolumn{4}{|c|}{ All groups together $(n=62)$} \\
\hline SCEs & $(n=31)$ & $(n=31)$ & \multirow{3}{*}{0.463} \\
\hline Mean (SD) & $5.60(1.59)$ & $5.55(2.05)$ & \\
\hline Median (Q1-Q3) & $5.21(4.28-6.93)$ & $5.19(3.91-6.85)$ & \\
\hline \multicolumn{4}{|l|}{ CRC patients $(n=22)$} \\
\hline SCEs & $(n=10)$ & $(n=12)$ & \multirow{3}{*}{0.407} \\
\hline Mean (SD) & $4.40(0.79)$ & $4.50(1.16)$ & \\
\hline Median (Q1-Q3) & $4.57(3.50-4.97)$ & $4.43(3.44-5.21)$ & \\
\hline \multicolumn{4}{|c|}{ Hospital-based controls $(n=16)$} \\
\hline SCEs & $(n=9)$ & $(n=7)$ & \multirow{3}{*}{0.121} \\
\hline Mean (SD) & $4.70(0.96)$ & $4.03(1.24)$ & \\
\hline Median (Q1-Q3) & $4.28(4.16-5.21)$ & $4.65(2.75-5.11)$ & \\
\hline \multicolumn{4}{|c|}{ Laboratory staff $(n=24)$} \\
\hline SCEs & $(n=12)$ & $(n=12)$ & \multirow{3}{*}{0.332} \\
\hline Mean (SD) & $7.27(0.83)$ & $7.50(1.56)$ & \\
\hline \multirow[t]{3}{*}{ Median (Q1-Q3) } & $7.21(6.64-7.72)$ & $7.47(6.28-8.81)$ & \\
\hline & \multicolumn{3}{|l|}{ Level of fruit consumption } \\
\hline & Low $<7.90$ servings/week & High $\geq 7.90$ servings/week & $p$ \\
\hline \multicolumn{4}{|c|}{ All groups together $(n=62)$} \\
\hline SCEs & $(n=31)$ & $(n=31)$ & \multirow{3}{*}{0.292} \\
\hline Mean (SD) & $5.70(2.05)$ & $5.45(1.58)$ & \\
\hline Median (Q1-Q3) & $5.19(4.28-7.45)$ & $5.23(4.20-6.67)$ & \\
\hline \multicolumn{4}{|l|}{ CRC patients $(n=22)$} \\
\hline SCEs & $(n=10)$ & $(n=12)$ & \\
\hline Mean (SD) & $4.16(0.83)$ & $4.70(1.07)$ & 0.106 \\
\hline Median (Q1-Q3) & $4.10(3.48-4.84)$ & 4.77 (3.91-5.18) & \\
\hline
\end{tabular}


Table 3 continued

\begin{tabular}{lll}
\hline & Level of fruit consumption & \\
\cline { 2 - 3 } & Low $<7.90$ servings/week & High $\geq 7.90$ servings/week \\
\hline Hospital-based controls $(n=16)$ & $(n=8)$ & $(n=8)$ \\
SCEs & $4.53(1.42)$ & $4.28(0.76)$ \\
Mean (SD) & $4.95(3.51-5.16)$ & $4.18(3.72-4.96)$ \\
Median (Q1-Q3) & & \\
Laboratory staff $(n=24)$ & $(n=13)$ & $(n=11)$ \\
SCEs & $7.61(1.40)$ & $7.12(0.98)$ \\
Mean (SD) & $8.10(6.59-8.73)$ & $6.96(6.60-7.58)$ \\
Median (Q1-Q3) & & 0.169 \\
\hline
\end{tabular}

\section{Discussion}

Our study showed a protective effect of raw vegetables measured by the frequency of SCEs. The effect was observed, when different individuals were considered as being a healthy person, or a non-cancer patient requiring hospitalization or a colorectal cancer patient. Across all these individuals, an increase in consumption of raw vegetables was associated with a decrease in the frequency of SCEs in blood lymphocytes. The negative relationship was rather stable, as it was observed even after adjustment for several covariates.

SCEs are used to measure individual effects of exposure to mutagens. Vegetables are a source of many biological compounds that are considered to be protective against DNA damage. Oxidative stress in a cell leads to the DNA oxidation, which is finally controlled by the repair of the DNA. The availability of antioxidants (e.g., antioxidative vitamins) can decrease the level of oxidative stress and finally decrease the frequency of DNA damage [25]. One of the vitamins with antioxidative properties is vitamin A (carotenoids) [26]. The effect of vitamin A was observed in animal studies, which showed an inhibition of SCE frequencies induced by some carcinogens [27, 28]. In vivo investigations have shown that retinoids decrease genotoxicity, metabolic activation and bindings to the DNA of many carcinogens such as aflatoxin B [29], $\mathrm{N}$ nitrosamines [30] and dimethylbenz[a]anthracene [31]. There are also other compounds that may be responsible for the protective effect of vegetables such as vitamin $\mathrm{C}$ [32] or isothiocyanates [33] found in cruciferous vegetables. Although some studies failed to prove the protective effect of some dietary items such as vitamin C [8], this does not contradict our results. The purpose of our investigation was to assess the effect of vegetables as a whole, and we think that the protective effect of raw vegetables is related to the content of all beneficial dietary nutrients.
Our study failed to demonstrate any protective effect of cooked vegetables and fruits. There are some possible explanations. Firstly, in cooked vegetables, the content of vitamins and microelements is lowered after preparation [34]. Additionally, the range of consumption of cooked vegetables was very low in our study (Fig. 1). Finally, cooked vegetables may present a different dietary spectrum to raw vegetables, and thus, they may not be directly related to the decrease in SCE frequency. Regarding consumption of fruits, the effect was very weak, and statistically insignificant. At the moment, we cannot distinguish if this is an effect of a small sample size or, in fact, there is no relationship between number of fruit servings and the SCE frequency.

In our study, we did not observe a higher SCE frequency in CRC patients when compared to the two other that in control groups. In fact, the group of laboratory workers presented a higher SCE count. The finding with CRC patients is not surprising; as we analyzed blood lymphocytes for SCE frequency, and because we recruited for the study only sporadic CRC cases, their cancer risk was expected to be related mainly to the local tissue-related chromosomal instability and therefore was not observed at the level of the whole organisms. Similar results showing no differences between cancer cases and healthy controls were published before [35-37]. However, it is worth mentioning that study results are not consistent $[38,39]$ in this area.

In our study, the PRI was higher among colorectal cancer patients as compared to healthy laboratory workers, and also hospital-based controls presented higher PRI than the group of laboratory workers. The PHA-induced mitotic index in blood lymphocytes is a surrogate representing immune function and a potential of cell proliferation. Cell proliferation is associated with the pathogenesis of cancer [40] as it provides opportunities for genetic mutations. The proliferation of immune cells is a physiological process also observed in the presence of inflammation which was more likely to be observed among hospital-based controls. The differences in the PRIs between groups in our study 


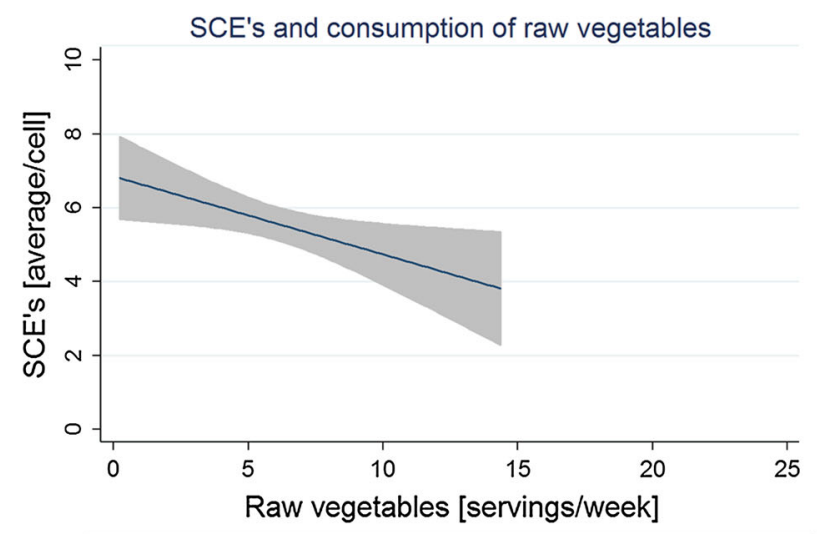

$95 \% \mathrm{Cl} \longrightarrow[\mathrm{SCE} ' \mathrm{~s}]=-0.21 *$ raw fruits] $(p<0.05)$
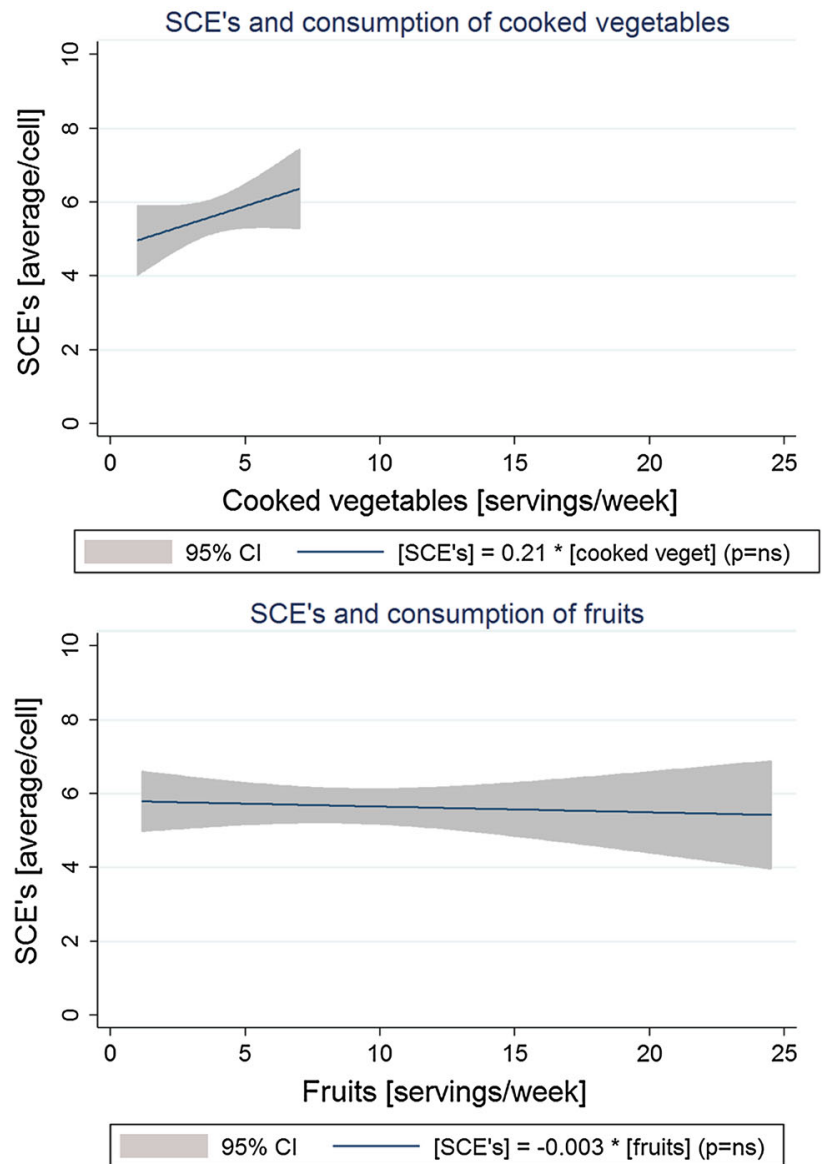

Fig. 1 Consumption of vegetables and fruits and SCE frequency (linear regression with $95 \%$ confidence intervals)

provide information about proliferative potentials across groups and the lowest value observed in the "healthy laboratory workers" group suggests that they were indeed healthy at a time of investigation.

Regarding the group of laboratory workers, the participants in this group were of two different professions. There were analytical chemists (six people) described under discussion as "people who were continuously exposed to several chemicals". As they were recruited voluntarily, there was a possibility that they perceived themselves as exposed to some risks and that is why they wanted to participate. The remaining 15 were also voluntarily recruited workers of the nuclear physics institute-apparently healthy with no signs or symptoms of a disease, but because of the nature of their work (some of them worked in laboratory units preparing slides of biological samples, and some others might be exposed to radiation as the exposure was present in some areas of the aforementioned institute)-they all together were named "laboratory workers". Thus, there were very likely people who had been exposed to several risks, and therefore, they were considered as a separate group. Although it was not possible to measure chemical compound exposure at the workplace of these individuals, other studies reported that an increased count of SCE frequency was observed after occupational exposure to formaldehyde [41, 42], benzene [43] and polycyclic aromatic hydrocarbons [44], as well as among interventional cardiology laboratory workers [45] and among nurses handling cytostatic drugs [46].

Possible limitations of the study

The presented study has also some limitations. One is its relatively small sample size across subgroups, and as a consequence any analysis performed in subgroups which were smaller than 40 individuals failed to show significant results.

Vegetables as well as fruits are very heterogeneous groups, with different amount of macro and micronutrients across items within the group. Thus, it is very difficult to answer which particular dietary components are responsible for the effect of raw vegetables. This is a point for discussion. We know that the size of the serving was standardized to achieve a kind of comparability in the content ("the amount of foods that provide a comparable amount of key nutrients from that food group") between different types of fruits and vegetables [47, 48]; however, the use of a serving concept is a kind of a trade-off between the possibility to link a particular dietary component with a biological outcome and the necessity to create some guidelines regarding dietary habits recommended for a population. Thus, our study considered the possibility of the effect of a particular group of dietary items (recommended fruits and vegetables), but (due to relatively small sample size) we were not able to assess the effects of micronutrients (i.e., vitamins).

Secondly, there were studies showing higher frequency of SCE among smokers, as compared to non-smokers [49, 50], some with [50] and some without [49] correlation with a number of cigarettes smoked daily. In our study, smokers have a slightly higher SCE frequency as compared to non- 
smokers (means 5.7 vs. 5.5; medians: 5.2 vs. 5.1, $p=0.698$ ), but this difference was not significant. There was also no difference in smoking frequency in CRC cases and hospital-based controls. Thus, we think that a distorting effect of smoking in the observed relationship between raw vegetables and SCE frequency in our study is rather unlikely. The high variability of vegetable consumption prevents us from investigating the role of vegetable subgroups. Moreover, diet may be also a source of heterocyclic amines. They are found in grilled fish and grilled meat, in juice from heated meat, and in stewed meat heated for a prolonged time [51]. As they are potentially mutagenic, the level of DNA damage depending on the level of exposure should be relatively low in our study, as only about 2 out of 38 of participants (for whom this information was available) consumed grilled meat on average more frequently than once per week.

The results of our study support the beneficial effect of consumption of a higher number of servings of raw vegetables; however, a problem may arise with regard to translating this information into practice. The SFFQ supported by standardized photographs of portion sizes was used to assess the size of a portion usually consumed. Results were recalculated into number of servings standardized to equal $80 \mathrm{~g}$ of eatable parts of vegetables (the same was for fruits). The calibration study, however, performed to assess the real level of consumption has shown that there is relatively high variability between the real size and the reported size of vegetables and fruits, and for the SFFQs prepared for the EPIC study (our questionnaire has been prepared with them), the real size of the serving of vegetables has been $72 \mathrm{~g}$ on average [52]. Nevertheless, even if the real size of a serving might be debatable, we believe that our study has shown the beneficial effect related to the number of servings of raw vegetables.

In summary, the results of our study performed across individuals with different characteristics have shown an inverse effect of consumption of raw vegetables on the damage of the DNA measured by SCE frequency. Thus, our study supports—on the cytogenetic level—epidemiologic investigations showing the beneficial role of raw vegetables. Further effort is required to determine the role of cooked vegetables and fruits.

Acknowledgments This research project is funded by the Polish National Science Centre in 2010-2013 (No. N N404 034039) - the principal investigator Aleksander Galas MD, PhD. Presented results were also supported by the data from the project (No. 6 P05D 00220) of Ministry of Science and Education-the principal investigator Prof. Wieslaw Jedrychowski, MD, PhD, and from the project (No. N N404 029635) of Polish National Science Centre-the principal investigator Prof. Antonina Cebulska-Wasilewska, PhD.

Conflict of interest The authors declare that they have no conflict of interest.

Open Access This article is distributed under the terms of the Creative Commons Attribution License which permits any use, distribution, and reproduction in any medium, provided the original author(s) and the source are credited.

\section{Appendix}

The part of the semi-quantitative food frequency questionnaire used to gather information about habitual consumption of vegetables and fruits. 


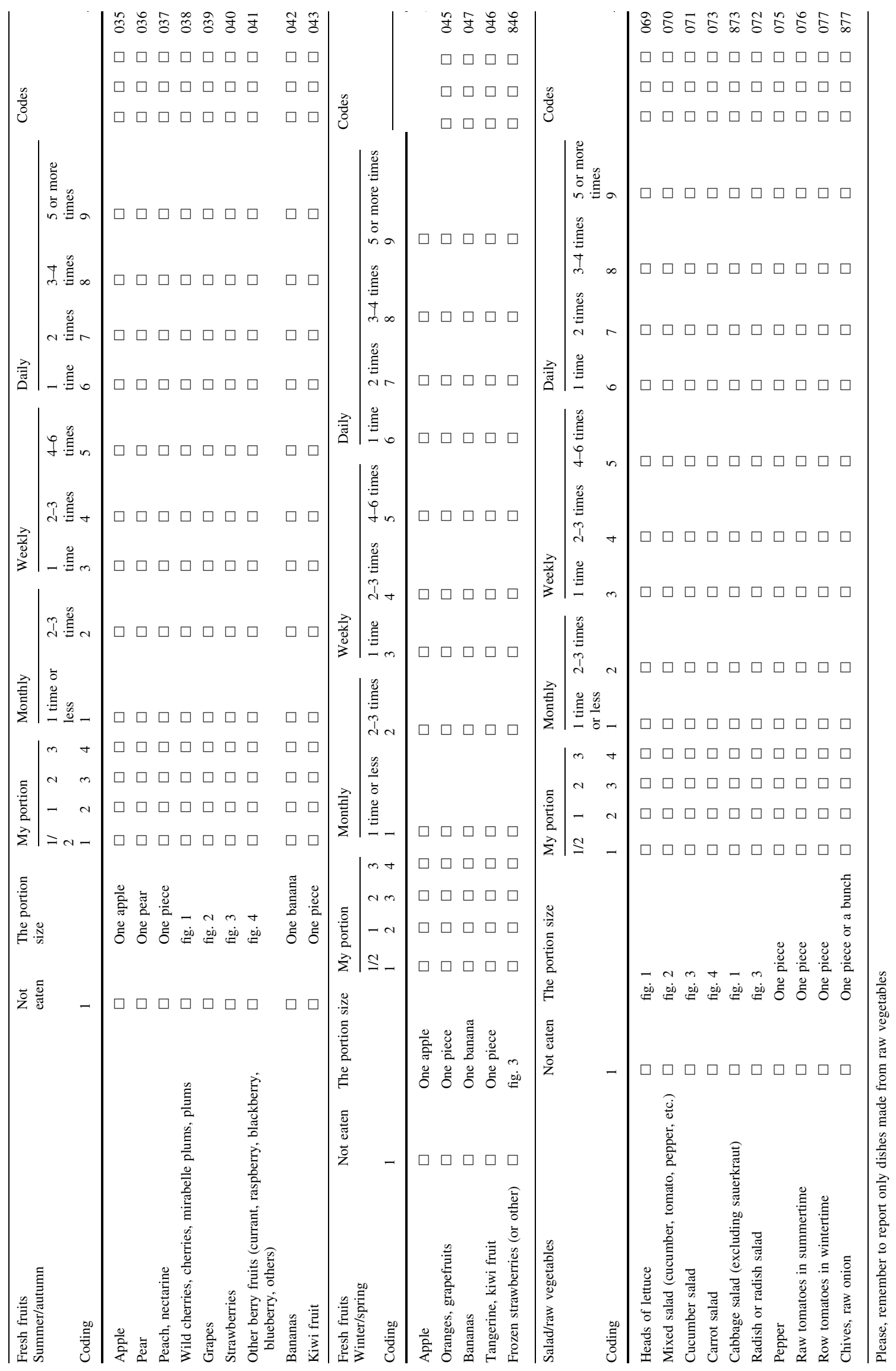




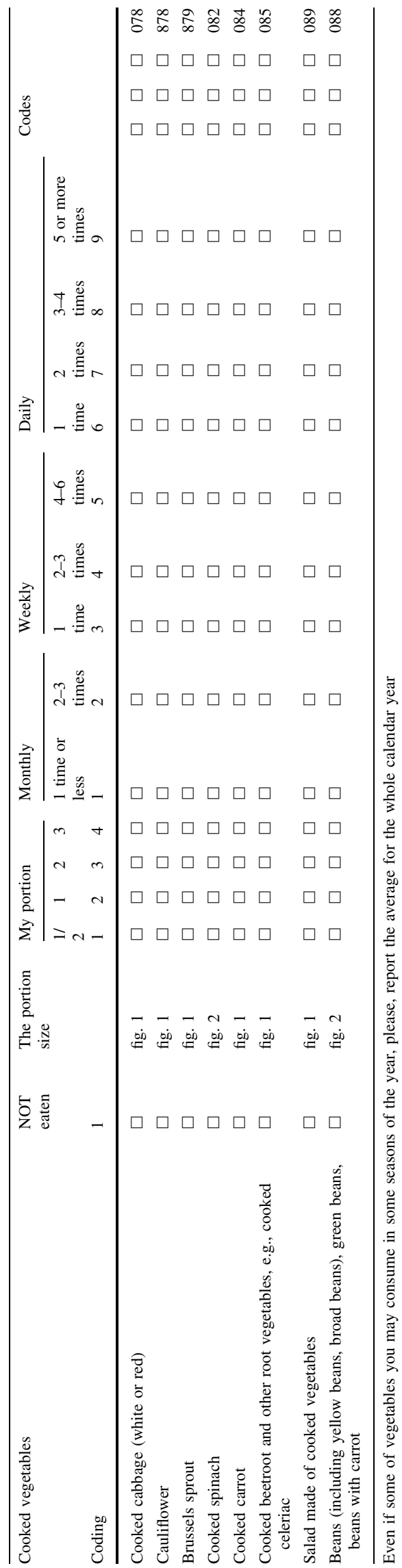

\section{References}

1. Wells PG, McCallum GP, Lam KC, Henderson JT, Ondovcik SL (2010) Oxidative DNA damage and repair in teratogenesis and neurodevelopmental deficits. Birth Defects Res C Embryo Today 90(2): 103-109

2. Das BC (1988) Factors that influence formation of sister chromatid exchanges in human blood lymphocytes. Crit Rev Toxicol 19(1):43-86

3. Lazutka JR (1995) Sister chromatid exchanges (SCEs) and high frequency cells (HFCs) in human population studies: principles of their analysis. Mutat Res 331(2):229-231

4. Frentz G, Wulf HC, Munch-Petersen B, Niebuhr E (1987) Normal sister chromatid exchange in lymphocytes from patients with multiple epidermal cancer? Arch Dermatol Res 279(3):180-183

5. Halliwell B (2007) Oxidative stress and cancer: have we moved forward? Biochem J 401(1):1-11

6. Sankaranarayanan K (1991) Ionizing radiation and genetic risks. III. Nature of spontaneous and radiation-induced mutations in mammalian in vitro systems and mechanisms of induction of mutations by radiation. Mutat Res 258(1):75-97

7. Halliwell B, Gutteridge JM, Cross CE (1992) Free radicals, antioxidants, and human disease: where are we now? J Lab Clin Med 119(6):598-620

8. Gordon M (1996) Dietary antioxidants in disease prevention. Nat Prod Rep 13(4):265-273

9. World Cancer Research Fund/American Institute for Cancer Research (2007) Food, nutrition, physical activity, and the prevention of cancer: a global perspective. AICR, Washington, DC, pp 77-115

10. Kalpana Deepa Priya D, Gayathri R, Gunassekaran GR, Murugan S, Sakthisekaran D (2013) Apoptotic role of natural isothiocyanate from broccoli (Brassica oleracea italica) in experimental chemical lung carcinogenesis. Pharm Biol 51(5):621-628. doi:10. 3109/13880209.2012.761242

11. Vanden Berghe W (2012) Epigenetic impact of dietary polyphenols in cancer chemoprevention: lifelong remodeling of our epigenomes. Pharmacol Res 65(6):565-576. doi:10.1016/j.phrs. 2012.03.007

12. Collins AR, Azqueta A, Langie SA (2012) Effects of micronutrients on DNA repair. Eur J Nutr 51(3):261-279. doi:10.1007/ s00394-012-0318-4

13. Mullner E, Brath H, Toferer D, Adrigan S, Bulla MT, Stieglmayer R et al (2013) Genome damage in peripheral blood lymphocytes of diabetic and non-diabetic individuals after intervention with vegetables and plant oil. Mutagenesis 28(2):205-211. doi:10.1093/mutage/ges073

14. Charron CS, Clevidence BA, Albaugh GA, Kramer MH, Vinyard BT, Milner JA et al (2013) Assessment of DNA damage and repair in adults consuming allyl isothiocyanate or brassica vegetables. J Nutr Biochem 24(5):894-902. doi:10.1016/j.jnutbio. 2012.06.004

15. Azqueta A, Costa S, Lorenzo Y, Bastani NE, Collins AR (2013) Vitamin C in cultured human (HeLa) cells: lack of effect on DNA protection and repair. Nutrients 5(4):1200-1217. doi:10.3390/ nu5041200

16. Caple F, Williams EA, Spiers A, Tyson J, Burtle B, Daly AK et al (2010) Inter-individual variation in DNA damage and base excision repair in young, healthy non-smokers: effects of dietary supplementation and genotype. Br J Nutr 103(11):1585-1593. doi:10.1017/S0007114509993540

17. Briviba K, Kulling SE, Moseneder J, Watzl B, Rechkemmer G, Bub A (2004) Effects of supplementing a low-carotenoid diet with a tomato extract for 2 weeks on endogenous levels of DNA single strand breaks and immune functions in healthy nonsmokers and smokers. Carcinogenesis 25(12):2373-2378 
18. Prieme H, Loft S, Nyyssonen K, Salonen JT, Poulsen HE (1997) No effect of supplementation with vitamin E, ascorbic acid, or coenzyme Q10 on oxidative DNA damage estimated by 8-oxo7,8-dihydro-2'-deoxyguanosine excretion in smokers. Am J Clin Nutr 65(2):503-507

19. Martins EA, Chubatsu LS, Meneghini R (1991) Role of antioxidants in protecting cellular DNA from damage by oxidative stress. Mutat Res 250(1-2):95-101

20. O'Brien NM, Woods JA, Aherne SA, O'Callaghan YC (2000) Cytotoxicity, genotoxicity and oxidative reactions in cell-culture models: modulatory effects of phytochemicals. Biochem Soc Trans 28(2):22-26

21. Jedrychowski W, Maugeri U, Pac A, Sochacka-Tatara E, Galas A (2008) Protective effect of fish consumption on colorectal cancer risk. Hospital-based case-control study in Eastern Europe. Ann Nutr Metab 53(3-4):295-302

22. Galas A, Augustyniak M, Sochacka-Tatara E (2013) Does dietary calcium interact with dietary fiber against colorectal cancer? A case-control study in Central Europe. Nutr J 12(1):134. doi:10. 1186/1475-2891-12-134

23. Bohlscheid-Thomas S, Hoting I, Boeing H, Wahrendorf J (1997) Reproducibility and relative validity of food group intake in a food frequency questionnaire developed for the german part of the EPIC project. European prospective investigation into cancer and nutrition. Int J Epidemiol 26(Suppl 1):S59-S70

24. Wolff S (1991) Biological dosimetry with cytogenetic end-points. In: Gledhill BL, Mauro F (eds) New horizons in biological dosimetry. Wiley-Liss, New York, pp 351-362

25. Collins AR, Horvathova E (2001) Oxidative DNA damage, antioxidants and DNA repair: applications of the comet assay. Biochem Soc Trans 29(Pt 2):337-341

26. Paiva SA, Russell RM (1999) Beta-carotene and other carotenoids as antioxidants. J Am Coll Nutr 18(5):426-433

27. Alaoui-Jamali MA, Belanger PM, Rossignol G, Castonguay A (1991) Metabolism, sister chromatid exchanges, and DNA singlestrand breaks induced by 4-(methylnitrosamino)-1-(3-pyridyl)-1butanone and their modulation by vitamin A in vitro. Cancer Res 51(15):3946-3950

28. Turkez H, Aydin E (2012) The protective role of ascorbic acid on imazalil-induced genetic damage assessed by the cytogenetic tests. Toxicol Ind Health 28(7):648-654. doi:10.1177/07482337 11420471

29. Busk L, Ahlborg UG (1980) Retinol (vitamin A) as an inhibitor of the mutagenicity of aflatoxin B. Toxicol Lett 6(4-5):243-249

30. Huang CC (1987) Retinol (vitamin A) inhibition of dimethylnitrosamine (DMN) and diethylnitrosamine (DEN) induced sisterchromatid exchanges in V79 cells and mutations in Salmonella/ microsome assays. Mutat Res 187(3):133-140

31. Budroe JD, Schol HM, Shaddock JG, Casciano DA (1988) Inhibition of 7,12-dimethylbenz[a]anthracene-induced genotoxicity in chinese hamster ovary cells by retinol and retinoic acid. Carcinogenesis 9(7):1307-1311

32. Arranz N, Haza AI, Garcia A, Delgado E, Rafter J, Morales P (2007) Effects of organosulfurs, isothiocyanates and vitamin C towards hydrogen peroxide-induced oxidative DNA damage (strand breaks and oxidized purines/pyrimidines) in human hepatoma cells. Chem Biol Interact 169(1):63-71

33. Hu R, Xu C, Shen G, Jain MR, Khor TO, Gopalkrishnan A et al (2006) Identification of Nrf2-regulated genes induced by chemopreventive isothiocyanate PEITC by oligonucleotide microarray. Life Sci 79(20):1944-1955

34. Pellegrini N, Chiavaro E, Gardana C, Mazzeo T, Contino D, Gallo $M$ et al (2010) Effect of different cooking methods on color, phytochemical concentration, and antioxidant capacity of raw and frozen brassica vegetables. J Agric Food Chem 58(7):4310-4321. doi:10.1021/jf904306r
35. Norppa H, Bonassi S, Hansteen IL, Hagmar L, Stromberg U, Rossner P et al (2006) Chromosomal aberrations and SCEs as biomarkers of cancer risk. Mutat Res 600(1-2):37-45

36. Gebhart E, Romahn R, Schneider A, Hoffmann M, Rau D, Tittelbach H (1993) Cytogenetic studies in lymphocytes of patients with rectal cancer. Environ Health Perspect 101(Suppl 3):169-175

37. Mertens F, Johansson B, Heim S, Mandahl N, Rydholm A, Mitelman F (1988) Normal frequency of chromosome breakage in lymphocytes from patients with musculoskeletal sarcoma. Cancer Genet Cytogenet 33(2):299-304

38. Mitra AB, Murty VV, Luthra UK (1982) Sister chromatid exchanges in leukocytes of patients with cancer of cervix uteri. Hum Genet 60(3):214-215

39. Adhvaryu SG, Rawal UM, Patel JV (1988) Elevated sister chromatid exchange frequencies in the lymphocytes of esophageal cancer patients. Cancer 61(9):1867-1871

40. Kosti O, Byrne C, Cocilovo C, Willey SC, Zheng YL (2010) Phytohemagglutinin-induced mitotic index in blood lymphocytes: a potential biomarker for breast cancer risk. Breast Cancer (Auckl) 4:73-83

41. Costa S, Garcia-Leston J, Coelho M, Coelho P, Costa C, Silva S et al (2013) Cytogenetic and immunological effects associated with occupational formaldehyde exposure. J Toxicol Environ Health A 76(4-5):217-229. doi:10.1080/15287394.2013.757212

42. Shaham J, Gurvich R, Kaufman Z (2002) Sister chromatid exchange in pathology staff occupationally exposed to formaldehyde. Mutat Res 514(1-2):115-123

43. Karacic V, Skender L, Bosner-Cucancic B, Bogadi-Sare A (1995) Possible genotoxicity in low level benzene exposure. Am J Ind Med 27(3):379-388

44. Wang Y, Yang H, Li L, Wang H, Xia X, Zhang C (2012) Biomarkers of chromosomal damage in peripheral blood lymphocytes induced by polycyclic aromatic hydrocarbons: a metaanalysis. Int Arch Occup Environ Health 85(1):13-25. doi:10. 1007/s00420-011-0629-4

45. Erol MK, Oztas S, Bozkurt E, Karakelleoglu S (2002) Sister chromatid exchange analysis and chromosoma aberration studies in interventional cardiology laboratory workers: one war follow up study. Jpn Heart J 43(2):159-166

46. Kasuba V, Rozgaj R, Garaj-Vrhovac V (1999) Analysis of sister chromatid exchange and micronuclei in peripheral blood lymphocytes of nurses handling cytostatic drugs. J Appl Toxicol 19(6):401-404

47. Cronin FJ, Shaw AM, Krebs-Smith SM, Marsland PM, Light L (1987) Developing a food guidance system to implement the dietary guidelines. J Nutr Ed 19(6):281-302

48. Welsh SO, Davis C, Shaw A (1993) USDA's food guide: background and development. U.S. Government Printing Office, Washington, DC. Human Nutrition Information Service Misc. Publication No. 1514

49. Kumar JV, Saraswathi T, Ranganathan K, Umadevi K, Joshua E, Rooban T (2012) Sister chromatid exchanges in smokers and smokers with alcohol habit. J Oral Maxillofac Pathol 16(3):338342. doi:10.4103/0973-029X.102480

50. Livingston GK, Fineman RM (1983) Correlation of human lymphocyte SCE frequency with smoking history. Mutat Res 119(1):59-64

51. Sugimura T, Wakabayashi K, Nakagama H, Nagao M (2004) Heterocyclic amines: mutagens/carcinogens produced during cooking of meat and fish. Cancer Sci 95(4):290-299

52. Slimani N, Kaaks R, Ferrari P, Casagrande C, Clavel-Chapelon F, Lotze G, Kroke A, Trichopoulos D, Trichopoulou A, Lauria C, Bellegotti M, Ocke MC, Peeters PH, Engeset D, Lund E, Agudo A, Larranaga N, Mattisson I, Andren C, Johansson I, Davey G, Welch AA, Overvad K, Tjonneland A, Van Staveren WA, Saracci R, Riboli E (2002) European Prospective Investigation into Cancer and Nutrition (EPIC) calibration study: rationale, design and population characteristics. Public Health Nutr 5:1125-1145 